\title{
Isolation and structures of some selenium and tellurium derivatives of $1,4,5,8,9,12$-hexabromododecahydrotriphenylene as co-crystals of triphenylene
}

\author{
POONAM RAJESH PRASAD ${ }^{\mathrm{a}}$, HARKESH B SINGH ${ }^{\mathrm{a}, *}$ and RAY J BUTCHER ${ }^{\mathrm{b}}$ \\ a Department of Chemistry, Indian Institute of Technology Bombay, Powai, Mumbai 400 076, India \\ ${ }^{b}$ Department of Chemistry, Howard University, Washington DC, 20059, USA \\ e-mail: chhbsia@chem.iitb.ac.in
}

MS received 28 May 2014; revised 8 July 2014; accepted 11 September 2014

\begin{abstract}
The synthesis and characterization of low-valent organoselenium and tellurium derivatives of hexabromododecahydrotriphenylene has been attempted. The reaction of hexabromododecahydrotriphenylene with in situ generated disodium dichalcogenides $\left(\mathrm{Na}_{2} \mathrm{E}_{2} ; \mathrm{E}=\mathrm{Se}, \mathrm{Te}\right)$ afforded insoluble chalcododecahydrotriphenylene derivatives, 20, 21 respectively. Attempted aromatization of 20 and 21 using DDQ (2, 3-dichloro-5, 6-dicyano-1,4-benzoquinone) as an oxidizing agent afforded the co-crystals. The hexaselenophenyl derivative, $\mathbf{2 2}$ and the hexaselenocyanate derivative $\mathbf{2 3}$ were synthesized by the reaction of in situ generated sodium arylselenolate/potassium selenocyanate with hexabromododecahydrotriphenylene, respectively. The compounds were characterized by common spectroscopic tools and a few by single crystal x-ray crystallographic studies.
\end{abstract}

Keywords. Hexabromododecahydrotriphenylene; organoselenide; -telluride; selenocyanate.

\section{Introduction}

The design and synthesis of polycyclic aromatic hydrocarbons (PAHs) have attracted considerable interest due to their potential application in various fields such as organic photovoltaic cells, semiconductors, liquid-crystalline materials and polymer research. ${ }^{1-3}$ Among PAHs, fullerene is one of the most studied molecules because of its symmetric structure and interesting semiconductor properties. The smallest subunit of fullerene is the bowl-shaped corannulene (1) and a concentric zwitterion 'annulene-within-an-annulene' resonance structure (1a) might contribute to the electronic properties of $\mathbf{1}$ (chart 1$){ }^{2}$

Similar to corannulene (1), the other simple symmetric structures of PAHs are correnes (2) and sumanene (4), which are not only attractive as siblings of fullerenes but attractive for their own physical and chemical properties. ${ }^{4}$ Triphenylene (3) is of special interest as a substrate for use as precursor for the synthesis of graphenes, buckminsterfullerenes, carbon nanotubes, as well as polycyclic heteroaromatics. It is known that the insertion of heteroatoms such as sulfur (5-8) into 3 enhances their electronic properties. Some other sulfur substituted PAHs synthesized for such studies are 9-15. ${ }^{3-6}$ The main aim of introducing chalcogen

\footnotetext{
*For correspondence
}

atoms into the frameworks of extended $\pi$-conjugated system of PAHs is to improve their inter-chain coupling and to suppress the Peierls transition. ${ }^{7-9}$ Among chalcogens, selenium and tellurium are more interesting due to their larger sizes and higher polarizability compared to sulfur. In the present study we report our attempts to insert heteroatoms like selenium and tellurium at the peripheral positions of the triphenylene rings using nucleophilic substitution reaction without any substitution on the triphenylene rings. During the course of the present study, Shao and co-workers ${ }^{10}$ have reported the insertion of sulfur and selenium heteroatoms at the peripheral positions of the triphenylene rings (16-17). In this case they succeeded in incorporating sulfur and selenium by electrophilic substitution reaction using $n$-BuLi as reagent followed by chalcogen $(\mathrm{S}, \mathrm{Se})$ insertion.

\section{Experimental}

\subsection{Materials}

Dry cyclohexanone (Spectrochem, India), $\mathrm{ZrCl}_{4}($ SigmaAldrich), bromine solution (Merck, India), potassium selenocyanate (Sigma-Aldrich), sodium borohydride (Merck, India), 2, 3-dichloro-5, 6-dicyanobenzoquinone (DDQ) (Sigma-Aldrich), selenium/tellurium powder 


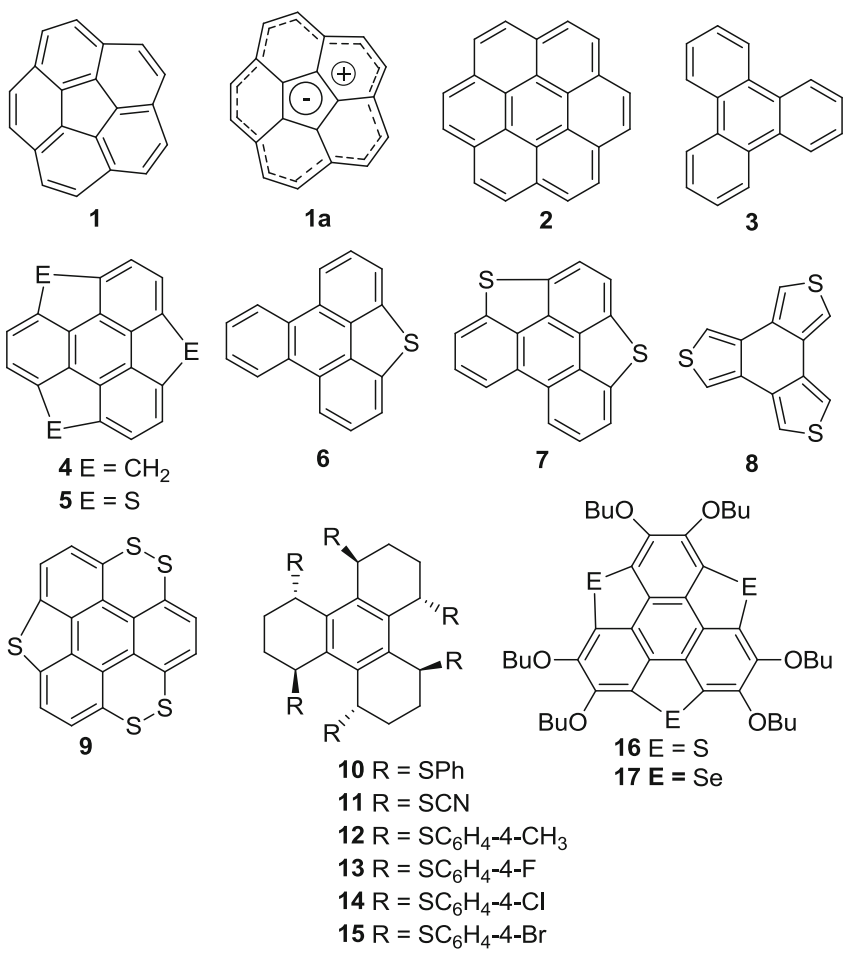

Chart 1. A few polycyclic aromatic hydrocarbons (PAHs) and heteroaromatics.

(Sigma-Aldrich) were used as received. Dodecahydrotriphenylene $(\mathbf{1 8})^{11}$ and 1,4,5,8,9,12-hexabromododecahydrotriphenylene (19) ${ }^{11}$ were prepared by following the literature procedures. The solvents were purified and dried by standard procedures and were freshly distilled prior to use.

\subsection{Physical measurements}

Melting points were recorded in capillary tubes. For most of the compounds, NMR spectra were recorded in $\mathrm{CDCl}_{3}$ solvent and for some using $\mathrm{CD}_{3}$ OD or DMSO$d_{6}$. The ${ }^{1} \mathrm{H}(400 \mathrm{MHz}),{ }^{13} \mathrm{C}(100 \mathrm{MHz}),{ }^{77} \mathrm{Se}(76.4$ $\mathrm{MHz})$ and ${ }^{125} \mathrm{Te}(126.3 \mathrm{MHz})$ spectra were recorded on a Bruker $400 \mathrm{MHz}$ spectrometer. Chemical shifts cited were referenced with respect to TMS for $\left({ }^{1} \mathrm{H}\right.$ and ${ }^{13} \mathrm{C}$ ) as internal standard and $\mathrm{Me}_{2} \mathrm{Se}$ (for ${ }^{77} \mathrm{Se}$ ), $\mathrm{Me}_{2} \mathrm{Te}$ (for ${ }^{125} \mathrm{Te}$ ) as external standards. Elemental analysis was performed on Carlo-Erba model 1106 and Eager 300 EA112 elemental analyzers. The IR spectra were recorded in the range of $400-4000 \mathrm{~cm}^{-1}$ by using $\mathrm{KBr}$ pellets for solid samples and as neat film for liquid samples on a Thermo Nicolet Avatar 320 FT-IR spectrometer. ESI-MS were recorded at room temperature on a Q-TOF micro (YA-105) mass spectrometer with electrospray ionization mode of analysis. In the case of isotopic patterns, the value given is for the most intense peak. In column chromatography, silica gel was used as a stationary phase whereas petroleum ether and ethyl acetate $(2 \%)$ were used as the mobile phase.

\subsection{Synthesis of hexaselenododecahydrotriphenylene (20)}

A stirred solution of disodium diselenide \{generated insitu by the reaction of sodium $(0.19 \mathrm{~g}, 8.42 \mathrm{mmol})$ and selenium $(0.66 \mathrm{~g}, 8.42 \mathrm{mmol})$ in dry THF in the presence of catalytic amount of naphthalene $\}$ was treated with precursor $19(1.00 \mathrm{~g}, 1.4 \mathrm{mmol})$ dissolved in DMF $(5 \mathrm{~mL})$ and DMSO $(10 \mathrm{~mL})$. The reaction mixture was stirred at room temperature for $12 \mathrm{~h}$. The resulting mixture was poured into water to get a yellow precipitate. This was collected by vacuum filtration, washed with water and ethanol and dried under vacuum to get a yellow solid. The crude product was insoluble (vide infra) in all common solvents including DMSO and was used as such for further reactions. Yield: $0.5 \mathrm{~g}(28 \%)$, M.p.: $>250^{\circ} \mathrm{C}$ Anal. Calc. for $\mathrm{C}_{18} \mathrm{H}_{18} \mathrm{Se}_{6}: \mathrm{C}, 30.53 ; \mathrm{H}, 2.56$. Found: C, 28.06; H, 2.09\%.

\subsection{Synthesis of tetratellurododecahydrotriphenylene (21)}

It was synthesized from the reaction of disodium ditelluride (generated in-situ) with $19(1.00 \mathrm{~g}, 1.4 \mathrm{mmol})$ in DMF $(5 \mathrm{~mL})$ and DMSO $(10 \mathrm{~mL})$, following the procedure used for the preparation of compound 20 . The crude product was insoluble (vide infra) in all common solvents including DMSO and was used as such for further reactions. Yield: $0.4 \mathrm{~g}(38 \%)$ M.p.: $>250^{\circ} \mathrm{C}$. Anal. Calc. for $\mathrm{C}_{18} \mathrm{H}_{18} \mathrm{Te}_{4}$ : C, 29.03; H, 2.44. Found: C, 28.03; $\mathrm{H}, 1.90 \%$.

\subsection{Synthesis of hexaselenophenyldodecahydrotri- phenylene (22)}

To an ethanolic solution of diphenyl diselenide $(0.51 \mathrm{~g}$, $1.63 \mathrm{mmol}$ ) was added an excess of sodium borohydride $(0.12 \mathrm{~g}, 3.26 \mathrm{mmol})$ at $0^{\circ} \mathrm{C}$. To this, a solution of $\mathbf{1 9}$ $(0.39 \mathrm{~g}, 0.54 \mathrm{mmol})$ in DMF $(5 \mathrm{~mL})$ was added and the reaction mixture allowed to stir for additional $6 \mathrm{~h}$ (monitored by TLC) at room temperature. The reaction mixture was then poured into water and the organic layer was extracted with diethyl ether and dried over sodium sulfate. The organic layer was evaporated to afford $\mathbf{2 2}$ as yellow oil. The oil was triturated with petroleum ether and diethyl ether (2:1) to give a white solid. Yield: 0.20 g (33\%). M.p. $237-239^{\circ}$ C. ${ }^{1} \mathrm{H}$ NMR (400 MHz, $\left.\mathrm{CDCl}_{3}\right): \delta(\mathrm{ppm}): 7.59-7.24(\mathrm{~m}, 30 \mathrm{H}), 5.59(\mathrm{~s}, 6 \mathrm{H})$, 2.87-2.80 (d, 6H), 1.99-1.97(d, 6H); ${ }^{13} \mathrm{C}$ NMR $(75$ 
$\left.\mathrm{MHz}, \mathrm{CDCl}_{3}\right): \delta 25.2,42.0,127.8,129.4,131.0,134.3$, 134.7; ${ }^{77} \mathrm{Se}$ NMR $\left(\mathrm{CDCl}_{3}\right): \delta$ 462. ES-Ms $\mathrm{m} / z$ calcd. for $\mathrm{C}_{54} \mathrm{H}_{48} \mathrm{Se}_{6}$ : 1170; found: $1016[\mathrm{M}-\mathrm{SePh}]^{+} ; 636$ [M-Se $\mathrm{Ph}_{4}+\mathrm{Na}$ ]. Anal.Calc. for $\mathrm{C}_{54} \mathrm{H}_{48} \mathrm{Se}_{6}:$ C, 55.40; H, 4.13. Found C, 54.68; H, 4.12\%.

\subsection{Synthesis of hexaselenocyanatedodecahydrotri- phenylene (23)}

To a stirred solution of $\mathbf{1 9}(0.50 \mathrm{~g}, 0.70 \mathrm{mmol})$ in dry tetrahydrofuran $(30 \mathrm{~mL})$ was added $\mathrm{KSeCN}(0.61 \mathrm{~g}$, $4.20 \mathrm{mmol}$ ) and the solution stirred for $10 \mathrm{~h}$ at room temperature. The resultant reaction mixture was then poured into water. The precipitate was filtered, washed with water and finally washed with methanol to get a pale yellow solid of 23. Yield: $0.21 \mathrm{~g}$ (34\%). M.p. 224-226 ${ }^{\circ} \mathrm{C} .{ }^{1} \mathrm{H}$ NMR (400 MHz, $\mathrm{CDCl}_{3}$ ), $\delta$ (ppm): $5.8(\mathrm{~s}, 6 \mathrm{H}), 2.84(\mathrm{~d}, J=12 \mathrm{~Hz}, 6 \mathrm{H}), 2.50(\mathrm{~d}, J=$ $12 \mathrm{~Hz}, 6 \mathrm{H}) ;{ }^{13} \mathrm{C}$ NMR $\left(75 \mathrm{MHz}, \mathrm{CDCl}_{3}\right), \delta(\mathrm{ppm})$ : 25.23, 26.22, 44.31, 67.13, 104.39, 134.42; ${ }^{77} \mathrm{Se}$ NMR $\left(\mathrm{CDCl}_{3}\right): \delta$ 411. ES-MS $\mathrm{m} / z$ calcd. for $\mathrm{C}_{24} \mathrm{H}_{18} \mathrm{Se}_{6} \mathrm{~N}_{6}$ : 864; found: $883[\mathrm{M}+\mathrm{K}]^{+}$; IR $\left(\mathrm{KBr}, \mathrm{cm}^{-1}\right): 2148.4$ $\left(v_{\mathrm{C} \equiv \mathrm{N}}\right)$; Anal.Calc. for $\mathrm{C}_{24} \mathrm{H}_{18} \mathrm{Se}_{6} \mathrm{~N}_{6}$ : C, 33.36; $\mathrm{H}, 2.10$; $\mathrm{N}, 9.72$. Found C, 34.13; H, 1.95; N, 7.562\%.

\subsection{Synthesis of selenotriphenylene (24-25)}

The crude solid of $20(1.0 \mathrm{~g})$ was suspended in dry chlorobenzene $(20 \mathrm{~mL})$ containing DDQ and refluxed for $12 \mathrm{~h}$. After this, it was allowed to cool to the room temperature. The reaction mixture was washed with aqueous $\mathrm{Na}_{2} \mathrm{SO}_{3}$ solution until the solution became colourless. The organic layer was dried over $\mathrm{Na}_{2} \mathrm{SO}_{4}$ and concentrated under reduced pressure to afford a residue, which was purified by chromatography on silica gel using petroleum ether and ethyl acetate $(2 \%)$ to get a mixture of products. The isolation of these compounds was very difficult due to their similar polarity and sensitivity to decomposition to form $\mathbf{3}$. Hence the compounds were characterized as mixture (vide infra). Yield: 0.22 g. M.p. $>250^{\circ} \mathrm{C}$ (decomp.) ${ }^{1} \mathrm{H}$ NMR (400 $\mathrm{MHz}, \mathrm{CDCl}_{3}$ ) mixture of $\mathbf{3 , 2 4}$ and 25, $\delta$ (ppm): 8.65$8.64(\mathrm{~m}, 2 \mathrm{H}), 8.63-8.51(\mathrm{~m}, 2 \mathrm{H}), 8.40(\mathrm{~d}, 2 \mathrm{H}), 8.07(\mathrm{~d}$, 2H), $7.76(\mathrm{~d}, 2 \mathrm{H}), 7.6(\mathrm{~m}, 2 \mathrm{H}) ;{ }^{13} \mathrm{C}$ NMR $(75 \mathrm{MHz}$, $\left.\mathrm{CDCl}_{3}\right), \delta(\mathrm{ppm}): 118.0,118.16,123.4,123.6,124.0$, $124.1,124.3,127.2,127.3,127.4,127.5,127.6,127.7$, $130.0,130.1,130.3,130.5,130.5,130.6,133.4 ; 133.6$, 138.8, $139.0 ;{ }^{77} \mathrm{Se} \mathrm{NMR}\left(\mathrm{CDCl}_{3}\right): \delta(\mathrm{ppm}): 498,459$; ES-MS $m / z$ calcd. for $\mathrm{C}_{36} \mathrm{H}_{18} \mathrm{Se}_{3}$ : 689; found: 690 $[\mathrm{M}+1] ; 611\left[\mathrm{C}_{18} \mathrm{H}_{8} \mathrm{Se}_{2}+\mathrm{C}_{18} \mathrm{H}_{12}+\mathrm{H}\right]^{+}$.

The experiment was repeated two more times and similar results were obtained. The three elemental analysis values of the mixtures of compounds $\mathbf{3}$ and 24, 25 before crystallization (from powder) are given below:

(i) Anal.Calcd. for $\mathrm{C}_{54} \mathrm{H}_{30} \mathrm{Se}_{3}: \mathrm{C}, 70.83 ; \mathrm{H}, 3.30$. Found: C, 70.50; H, 4.07\%.

(ii) Anal.Calcd. for $\mathrm{C}_{54} \mathrm{H}_{30} \mathrm{Se}_{3}: \mathrm{C}, 70.83 ; \mathrm{H}, 3.30$. Found: C, 73.61; H, 3.76\%.

(iii) Anal.Calcd. for $\mathrm{C}_{54} \mathrm{H}_{30} \mathrm{Se}_{3}: \mathrm{C}, 70.83 ; \mathrm{H}, 3.30$. Found: C, 73.57; H, 3.07\%.

After column chromatography and repeated crystallizations, the elemental analysis data obtained on crystals are given below. The elemental analysis data and other data (vide infra) showed it to be co-crystal of compounds 3 and $\mathbf{2 4}$.

(i) Anal.Calcd. for $\mathrm{C}_{18} \mathrm{H}_{11.64} \mathrm{Se}_{0.36}$ : C, 84.33; H, 4.57. Found: C, 84.51; H, 4.36\%.

(ii) Anal.Calcd. for $\mathrm{C}_{18} \mathrm{H}_{11.59} \mathrm{Se}_{0.41}$ : C, 83.07; H, 4.49. Found: C, 83.88; $\mathrm{H}, 4.82 \%$.

\subsection{Synthesis of tellurotriphenylene (26)}

Similarly, the crude solid of 21 ( $1.0 \mathrm{~g})$ was suspended in dry chlorobenzene $(20 \mathrm{~mL})$ containing DDQ and refluxed for $12 \mathrm{~h}$ and following a procedure similar to that used for the synthesis of 24-25. The yellow solid obtained was purified by column chromatography and it always eluted as a mixture of two components $\mathbf{3}$ and $\mathbf{2 6}$. Yield: 0.14 g. M.p. $>250^{\circ} \mathrm{C}$ (decomp.). ${ }^{1} \mathrm{H}$ NMR (400 $\mathrm{MHz}, \mathrm{CDCl}_{3}$ ) mixture of $\mathbf{3}$ and $\mathbf{2 6}, \delta(\mathrm{ppm}): 8.65-8.64$ $(\mathrm{m}, 2 \mathrm{H}), 8.57(\mathrm{~d}, 2 \mathrm{H}), 8.02(\mathrm{~d}, 2 \mathrm{H}), 7.60(\mathrm{~d}, 2 \mathrm{H}) ;{ }^{125} \mathrm{Te}$ NMR $\left(\mathrm{CDCl}_{3}\right): \delta 625 ;$ ES-MS: m/z (\%) $479[\mathrm{M}]^{+}$. (i) Anal.Calcd. for $\mathrm{C}_{72} \mathrm{H}_{46} \mathrm{Te}:\left(\mathrm{C}_{18} \mathrm{H}_{12}: \mathrm{C}_{18} \mathrm{H}_{8} \mathrm{Te}, 3: 1\right) \mathrm{C}$, 83.25; H, 4.46; Found: C, 84.28; H, 4.68\%.

The experiment was repeated twice and different results were obtained.

Anal. cacld for $\mathrm{C}_{72} \mathrm{H}_{46} \mathrm{Te}\left(\mathrm{C}_{18} \mathrm{H}_{12}: \mathrm{C}_{18} \mathrm{H}_{8} \mathrm{Te}, 8: 1\right)$ : $\mathrm{C}$, 89.25; H, 4.90; Found C, 89.48; H, 5.06\%.

\section{$2.9 X$ X-ray data collection and structure refinement}

The single crystal x-ray diffraction measurements compounds 3, 3-24 a, b, c (as co-crystal) and 3-26 (as cocrystals) were performed by using an Oxford Diffraction Gemini Diffraction measurements device with graphite monochromated MoK/ $\alpha$ radiation $(\lambda=0.7107$ $\AA$ ). The structures were determined by routine heavyatom method using SHELXS $97^{12}$ (Fourier methods) and refined by full-matrix least-squares with the nonhydrogen atom anisotropic and hydrogen atoms with fixed isotropic thermal parameters of $0.07 \AA$ by means of SHELXS 97 program. ${ }^{13}$ Scattering factors were from 
common sources. ${ }^{14}$ The crystallographic data for 3 , cocrystals of 3-24(a, b, c) and co-crystal of 3-26 are given in table 1.

\section{Results and Discussion}

\subsection{Synthesis}

The precursor, 1, 4, 5,8, 9, 12-hexabromododecahydrotriphenylene 19, was prepared by the reaction of dodecahydrotriphenylene $\mathbf{1 8}$ with bromine following the literature procedure. ${ }^{11,15}$ Organochalcogen derivatives 20 and 21 were synthesized by the reaction of $\mathbf{1 9}$ with in situ generated $\mathrm{Na}_{2} \mathrm{E}_{2}(\mathrm{E}=\mathrm{Se}$ and $\mathrm{Te})$ at room temperature (scheme 1). Compounds 20 and 21 were obtained as yellow and as black solids, respectively. The crude products could not be purified further and characterized properly owing to their poor solubility in the common organic solvents and were used as obtained for further reactions. Wei et al. have also obtained a similar insoluble product during the reaction of $\mathbf{1 9}$ with sodium sulfide. ${ }^{11}$ The elemental analysis indicated the formation of the desired products $\mathbf{2 0}$ and $\mathbf{2 1}$. The FT-IR spectra of $\mathbf{2 0}$ and $\mathbf{2 1}$ showed a different pattern as compared to precursor 19. Compound 22 was synthesized by the reaction of $\mathrm{PhSeNa}$ with 19 at $0^{\circ} \mathrm{C}$. The elemental analysis suggested the formation of compound $\mathbf{2 2}$. The synthesis of the selenocyanate derivative, $\mathbf{2 3}$ was accomplished by the addition of $\mathrm{KSeCN}$ to a tetrahyrofuran solution of $\mathbf{1 9}$ at room temperature (scheme 1).

The ${ }^{1} \mathrm{H}$ NMR spectrum of $\mathbf{2 2}$ exhibits signals in the range of 7.41-7.25 ppm corresponding to the aromatic protons, a signal at $5.53 \mathrm{ppm}$ for $\mathrm{CH}$ protons adjacent to the selenium atoms and other signals in the range of 2.57-1.98 ppm for $\left(\mathrm{CH}_{2}\right)$ protons. The $\mathrm{CH}$ protons adjacent to the selenium atoms are shifted upfield (5.53 ppm) when compared to the $\mathrm{CH}$ protons adjacent to bromine atoms in precursor 19 (6.13 ppm). Similarly, in the case of selenocyanate $\mathbf{2 3}$, the $\mathrm{CH}$ protons appeared in the upfield region $(5.78 \mathrm{ppm})$ as compared to the precursor 19 and the alicyclic protons were observed in the region of 3.59-2.47 ppm. The ${ }^{77} \mathrm{Se}$ NMR signal for 22 was observed at $462 \mathrm{ppm}$ which is slightly more $(\sim 50 \mathrm{ppm})$ downfield shifted as compared to that expected for monoselenides. ${ }^{16}$ This value of $462 \mathrm{ppm}$ is also downfield shifted as compared to bis(2formylphenyl)selenide (393 ppm). ${ }^{17}$ For selenocyanate 23, the ${ }^{77} \mathrm{Se}$ NMR chemical shift was $411 \mathrm{ppm}$, which is close to the chemical shifts reported for the related RSe$\mathrm{C} \equiv \mathrm{N}$ derivatives. ${ }^{18}$ The ${ }^{13} \mathrm{C}$ NMR spectrum of $\mathbf{2 2}$ shows seven peaks expected for the seven carbons, which are

Table 1. Crystal data and structure refinement for co-crystals of 3, 3-24 (a,b,c) and 3-26.

\begin{tabular}{|c|c|c|c|c|c|}
\hline Parameter & 3 & $3-24 a$ & $3-24 b$ & $3-24 c$ & $3-26$ \\
\hline Formula & C18 H18 & C18 H11.64 Se0.36 & C18 H11.70 Se0.30 & C18 H11.59 Se0.41 & C18 H11.98 Te0.02 \\
\hline Formula Weight & 228.28 & 256.17 & 251.55 & 259.44 & 230.79 \\
\hline Temperature & $123(2) \mathrm{K}$ & $296(2) \mathrm{K}$ & $123(2) \mathrm{K}$ & $123(2) \mathrm{K}$ & $123(2) \mathrm{K}$ \\
\hline Wavelength $(\AA)$ & 1.54184 & 1.54178 & 1.54184 & 1.54184 & 0.71073 \\
\hline Crystal System & Orthorhombic & Orthorhombic & Orthorhombic & Orthorhombic & Orthorhombic \\
\hline Space Group & $\mathrm{P} 2{ }_{1} 2_{1} 2_{1}$ & $\mathrm{P} 2{ }_{1} 2_{1} 2_{1}$ & $\mathrm{P} 2{ }_{1} 2{ }_{1}{ }_{1}$ & $\mathrm{P} 2{ }_{1} 2_{1} 2_{1}$ & $\mathrm{P} 2{ }_{1} 2_{1} 2_{1}$ \\
\hline $\mathrm{a}(\AA)$ & $5.26628(17)$ & $5.2507(5)$ & $5.27903(15)$ & $5.2728(3)$ & $5.25999(1)$ \\
\hline $\mathrm{b}(\AA)$ & $12.9714(4)$ & $13.804(2)$ & $13.2092(9)$ & $13.3470(11)$ & $12.9652(4)$ \\
\hline$c(\AA)$ & $16.6563(5)$ & $16.782(2)$ & $16.7456(6)$ & $16.7410(11)$ & $16.6417(4)$ \\
\hline$\alpha\left(^{\circ}\right)$ & 90 & 90 & 90 & 90 & 90 \\
\hline$\beta\left(^{\circ}\right)$ & 90 & 90 & 90 & 90 & 90 \\
\hline$\gamma\left({ }^{\circ}\right)$ & 90 & 90 & 90 & 90 & 90 \\
\hline Volume (Å3) & $1137.81(6)$ & $1216.4(3)$ & $1167.70(9)$ & $1178.17(14)$ & $1134.91(5)$ \\
\hline $\mathrm{Z}$ & 4 & 4 & 4 & 4 & 4 \\
\hline $\mathrm{D}(\mathrm{Mg} / \mathrm{m} 3)$ & 1.333 & 1.399 & 1.431 & 1.463 & 1.351 \\
\hline Abs. Coef. (mm-1) & 0.572 & 1.786 & 1.645 & 1.996 & 0.126 \\
\hline Crystal Size (mm) & $\begin{array}{l}0.4 \times 0.28 \\
\times 0.17\end{array}$ & $\begin{array}{l}0.49 \times 0.15 \\
\times 0.06\end{array}$ & $\begin{array}{l}0.45 \times 0.12 \\
\times 0.08\end{array}$ & $\begin{array}{l}0.48 \times 0.15 \\
\times 0.10\end{array}$ & $\begin{array}{l}0.50 \times 0.23 \\
\times 0.13\end{array}$ \\
\hline Total Reflections & 7640 & 8010 & 2717 & 2687 & 31286 \\
\hline Unique Ref. (Rint) & $2324(0.0375)$ & $2489(0.0349)$ & $1832(0.0287)$ & $1899(0.0208)$ & $7319(0.0472)$ \\
\hline Abs. Correction & Multi-scan & Multi-scan & Multi-scan & Analytical & Analytical \\
\hline Tmin \& Tmax & $0.956,1.000$ & $0.702,1.000$ & $0.622,1.000$ & $0.560,0.828$ & $0.898,0.962$ \\
\hline R1, wR2 & $0.055,0.151$ & $0.080,0.248$ & $0.062,0.167$ & $0.0389,0.112$ & $0.0639,0.1501$ \\
\hline $\begin{array}{l}\text { Diff. peak \& hole } \\
\text { (e.̊3) }\end{array}$ & $0.95,-0.195$ & $0.73,-0.21$ & $0.37,-0.41$ & $0.28,-0.13$ & $0.48,-0.34$ \\
\hline
\end{tabular}




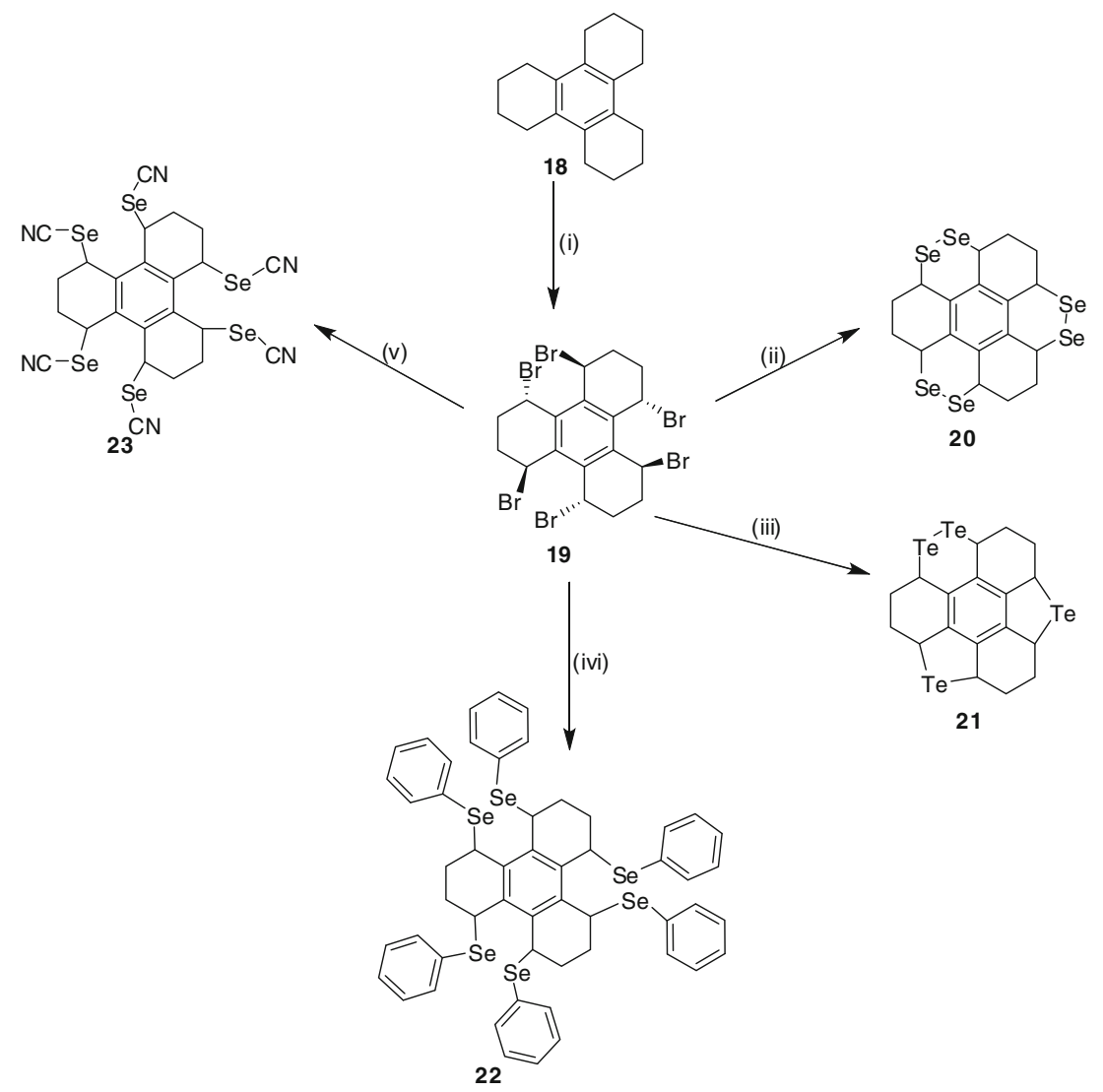

Scheme 1. Reagents and conditions: (i) $\mathrm{Br}_{2}$, dry $\mathrm{CCl}_{4}$; (ii) $\mathrm{Na}_{2} \mathrm{Se}_{2}$, THF, 24 h, r.t.; (iii) $\mathrm{Na}_{2} \mathrm{Te}_{2}$, THF, 24 h, r.t.; (iv) $\mathrm{PhSeNa}$, dry $\mathrm{EtOH}$; (v) $\mathrm{KSeCN}$, dry THF, 10 h, r.t.

significantly upfield shifted compared to the precursor 19. In the FT-IR spectrum of compound $\mathbf{2 3}$, the absorption at $2148 \mathrm{~cm}^{-1}$ is assigned to $v \mathrm{C} \equiv \mathrm{N}$ stretching. In the mass spectrum of $\mathbf{2 3}$, the molecular ion peak was observed at $m / z 887[\mathrm{M}+\mathrm{Na}]^{+}$. However, in the case of selenocyanate 22, the molecular ion peak was not observed and the base peak observed at $m / z 1016$ corresponded to $[\mathrm{M}-\mathrm{SePh}]^{+}$where $\left(\mathrm{M}=\mathrm{C}_{54} \mathrm{H}_{48} \mathrm{Se}_{6}\right)$ and $m / z 636$ corresponding to the $\left[\mathrm{C}_{30} \mathrm{H}_{28} \mathrm{Se}_{3}+\mathrm{Na}\right]^{+}$.

Aromatization of 20-21 to obtain organoselenide 2425/and -telluride 26 was attempted using DDQ as the oxidizing agent. The resulting derivatives 24-25 and telluride 26 were obtained as mixture containing 3 in very low yields respectively (scheme 2). However, when the reaction mixture was refluxed for a short period of time, most of the starting material was found to have remained unreacted. The purification of the aromatized organochalcogenides (24-25 and 26) was extremely difficult by usual methods (recrystallization and column chromatography) due to their similar polarity and sensitive nature of the compounds which decompose to triphenylene (3). It is worth mentioning that Klemm et al. have also reported to get a mixture of 3, 6 and 7 during the preparation of 7 in low

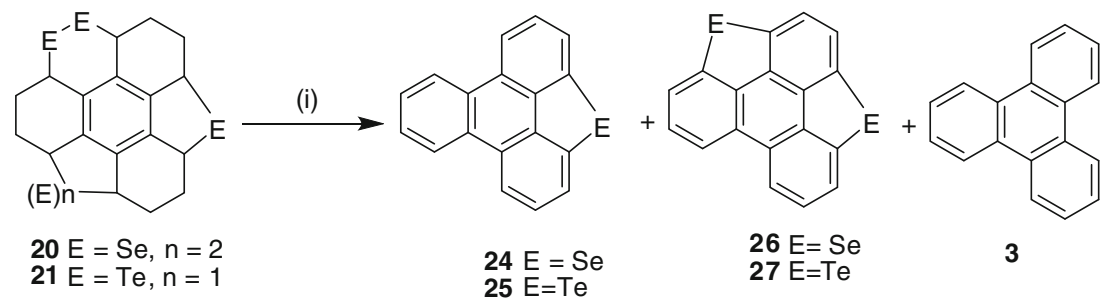

Scheme 2. Reagents and conditions: (i) DDQ, $\mathrm{PhCl}$, reflux, $10 \mathrm{~h}$. 
yields by the direct reaction of triphenylene (3) with hydrogen sulfide in the presence of heterogeneous catalyst at high temperature temperature $\left(500-550^{\circ} \mathrm{C}\right) .{ }^{19}$ Similarly, Imamura's group prepared trithiosumane (5) in $2 \%$ yield by flash vacuum pyrolysis $(\mathrm{FVP})^{20}$ and very recently Wei and co-workers synthesized the polycyclic pentathioaromatic (9) by a modified procedure in $20 \%$ yield. ${ }^{11}$ Here, it might be difficult to introduce selenium or tellurium at the peripheral positions of triphenylene 3 rings simultaneously owing to their larger size. The existence of the mixture of compounds was inferred from the elemental analysis. The elemental analysis showed different values for each preparation. In the elemental analysis data, the carbon percentage was very high $(\mathrm{C}=80-89 \%)$ and indicated the presence of the hydrocarbon (triphenylene $\mathbf{3}$ ) as the major impurity. Several attempts were made to isolate pure $\mathbf{2 4}$ and $\mathbf{2 5}$ (selenide) or $\mathbf{2 6}$ (telluride), however, every time elemental analysis showed different values. This observation was further corroborated by single crystal $\mathrm{x}-$ ray structure analysis (vide infra). After crystallization, the elemental analysis ratio was different than the ratio found for the powdered (crude) samples. In the mass spectrum of the mixture of selenides, the molecular ion peaks were observed at $m / z 315[\mathrm{M}+\mathrm{Na}]^{+}$for $\mathbf{2 4}$ and at $m / z 392[\mathrm{M}+\mathrm{Na}]^{+}$for 25 . It also showed the combined peak for $\mathbf{2 4 + 2 5}$ at $690[\mathrm{M}+1]^{+}$. However, the single crystal $\mathrm{x}$-ray structure analysis indicated the presence of only one selenium compound $\mathbf{2 4}$ (vide infra) along with 3. Though in the case of the tellurium derivative, the molecular ion peak observed at $m / z 447$ for $[\mathrm{M}]^{+}$ which indicated that two tellurium atoms were present at the peripheral positions of the triphenylene rings, i.e. formation of 27, the single crystal X-ray structure analysis again indicated the presence of only one tellurium compound (26) in small ratio (vide infra) along with $\mathbf{3}$.

The ${ }^{1} \mathrm{H}$ NMR spectrum of the mixture of $\mathbf{3}, \mathbf{2 4}$ and 25 (powder) showed the expected three sets of peaks in the region of $8.65-7.57 \mathrm{ppm}$ corresponding to the $\mathbf{3}$ (8.55 and $7.56 \mathrm{ppm}), \mathbf{2 4}$ (8.39 and $8.05 \mathrm{ppm}$ ) and 25 (8.65 and $7.78 \mathrm{ppm})$. It was further corroborated by ${ }^{13} \mathrm{C}$ NMR spectrum. The ${ }^{13} \mathrm{C}$ NMR spectrum (after long time data accumulation) also showed expected twenty one peaks related to all three compounds $(\mathbf{3}, \mathbf{2 4}$ and 25). It was further confirmed by ${ }^{77} \mathrm{Se}$ NMR spectrum. In the ${ }^{77} \mathrm{Se} \mathrm{NMR,} \mathrm{two} \mathrm{peaks} \mathrm{were} \mathrm{observed} \mathrm{at}$ 498 and 459 ppm. Similar to the selenides $\mathbf{2 4}$ and $\mathbf{2 5}$, compounds $\mathbf{3}$, and $\mathbf{2 6}$ also showed a complex pattern in the ${ }^{1} \mathrm{H}$ NMR spectrum, however, the ${ }^{125} \mathrm{Te}$ NMR spectrum showed a single at $625 \mathrm{ppm}$. This is slightly upfield shifted $(\sim 37 \mathrm{ppm})$ compared to the reported monotelluride, bis[2-(phenylazo)phenyl- $C, N$ ]telluride (667 (667 ppm). ${ }^{21}$

\subsection{X-ray crystallographic study}

The crystal data for the 5 compounds are listed in table 1 . The structures of 4 co-crystals of triphenylene with various amounts mono-selenium and tellurium substituted triphenylene are reported as well as a low temperature structure of triphenylene itself.

The structure of triphenylene has previously been reported $^{22}$ but this structure was based on film data at room temperature whereas the present study reports the structure based on diffractometer data at $123 \mathrm{~K}$. Cocrystals of triphenylene with other arene type molecules have previously been reported ${ }^{23}$ and result in interesting architectures. ${ }^{24}$ Since this is a more accurate structure of the important arene, triphenylene (figure 1), some comparison with the earlier results should be made. In the original paper of Ahmed \& Trotter ${ }^{23}$ it was noted that the aromatic molecule as a whole was significantly non-planar while the central ring was basically planar. In addition, the non-planarity shown by the outer sixmembered rings showed a pattern where the two rings were displaced in one direction from this central plane while the other ring was displaced in the opposite direction. In the original paper the unique ring was labelled as $\mathrm{A}$ while the other two rings were labelled as $\mathrm{B}$ and C. In the present structure the A ring is $\mathrm{C} 3 \mathrm{C} 4 \mathrm{C} 11$ $\mathrm{C} 12 \mathrm{C} 13$ \& $\mathrm{C} 14$ while $\mathrm{B}$ corresponds to $\mathrm{C} 1 \mathrm{C} 2 \mathrm{C} 7$ C8 C9 \& C10 and C to C5 C6 C15 C16 C17 \& C18 (figure 1). For the central ring composed of $\mathrm{C} 1$ through C6, the rms deviation of the 6 fitted atoms is $0.0065(16)$ $\AA$ while each individual outer ring is also planar (rms

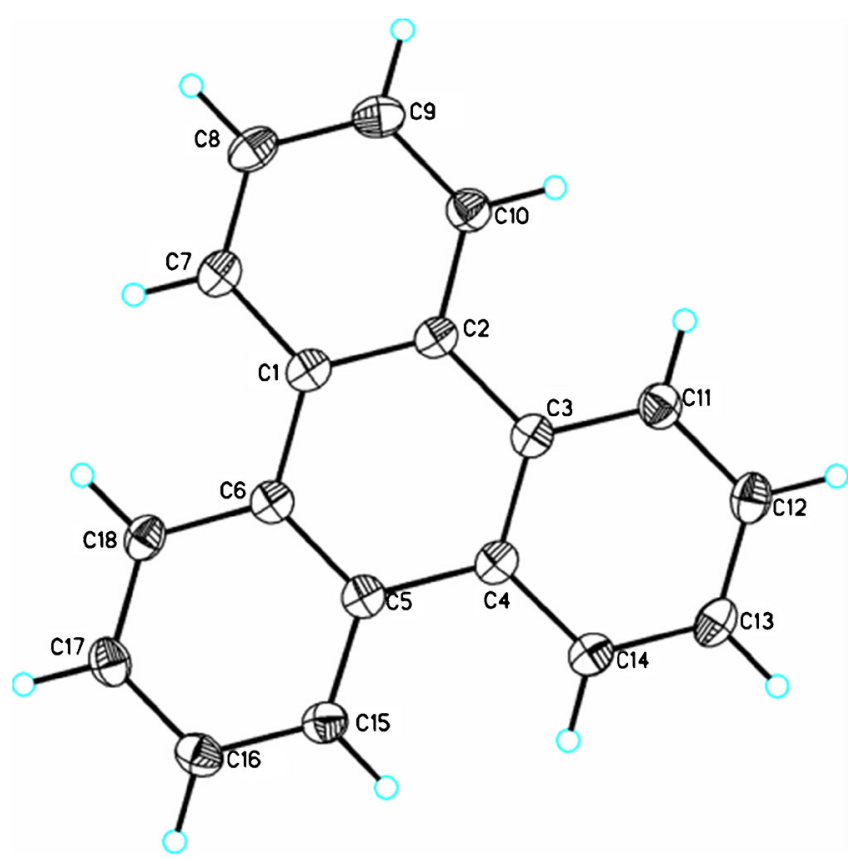

Figure 1. Molecular structure of $\mathbf{3}$. 
deviations of $0.0045(15), 0.0074(15)$ and $0.0033(15) \AA$ for $\mathrm{A}, \mathrm{B}$, and $\mathrm{C}$, respectively). The dihedral angles between the outer rings and central ring are $1.30(15)^{\circ}$, $2.42(16)^{\circ}$ and $2.19(15)^{\circ}$, for A, B and C, respectively. The central ring shows a pronounced pattern of alternating short and longer bonds with the shorter $\mathrm{C}-\mathrm{C}$ bonds being those which are part of the outer rings. The C$\mathrm{C}$ bond lengths for each outer ring also show a pattern with the $\mathrm{C}-\mathrm{C}$ bonds involving the carbon atoms of the central ring being significantly longer $\left(1.409(3)^{\circ}\right)$ than those involving only outer rings $\left(1.381(3)^{\circ}\right)$. As was noticed in the original report, the closest $\pi-\pi$ stacking involve ring $\mathrm{A}$ with rings $\mathrm{B}$ and $\mathrm{C}$ in neighbouring molecules (in this case, ring $\mathrm{A}$ corresponds to $\mathrm{C} 3 \mathrm{C} 4$ $\mathrm{C} 11 \mathrm{C} 12 \mathrm{C} 13$ and $\mathrm{C} 14$; ring $\mathrm{B}$ to $\mathrm{C} 1 \mathrm{C} 2 \mathrm{C} 7 \mathrm{C} 8 \mathrm{C} 9$ and $\mathrm{C} 10$; ring $\mathrm{C}$ to $\mathrm{C} 5 \mathrm{C} 6 \mathrm{C} 15 \mathrm{C} 16 \mathrm{C} 17 \mathrm{C} 18)$.

For the substituted triphenylenes there are three mono-Se substituted derivatives (3-24a, 3-24b, 3-24c) (as well as one mono-Te) substituted triphenylene (3-26). For the $\mathrm{Se}$ derivatives, the structure of 3-24a was carried out at room temperature (RT) with 0.36 Se substitution while there were two (3-24b and 3-24c) low temperature (LT) structures $(123 \mathrm{~K})$ with 0.30 and $0.41 \mathrm{Se}$ substitution. In addition, there was one (3-26) LT structure with Te substitution (0.02). The effect of the substitution for each can be found by comparison of the cell constants, metrical parameters and $\pi-\pi$ stacking interactions of each with the unsubstituted triphenylene structure. Each structure will

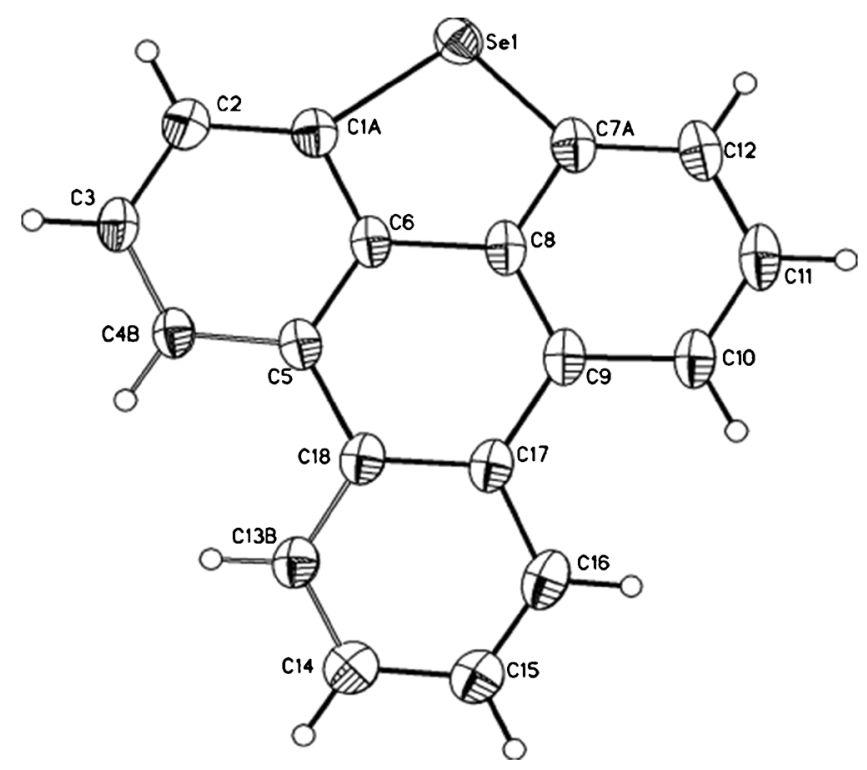

Figure 2. Molecular structure of 24: Selected bond $(\AA)$ lengths and bond angles $\left(^{\circ}\right)$ : $\operatorname{Se}(1)-C(7 A) 1.751(6)$, Se1$\mathrm{C}(1 \mathrm{~A})$ 1.904(5), C(7)-Se(1)-C(1A) 100.8(2), C(6)-C(1A)$\mathrm{Se}(1)$ 98.5(3), C(2)-C(1A)-Se(1) 141.5(4). be discussed in turn starting with 3-24a (figure 2). A direct comparison of cell constants is made difficult for this structure due to the differences in temperature between the two structures. Obviously it is generally expected that at the higher temperature the cell volume should be larger than at low temperature and this is observed. A more meaningful comparison will be made for the LT Se structures. As far as the Se substitution for this structure is concerned, all the spectroscopic evidence points to a mono substitution of the triphenylene skeleton. However, in the X-ray structure the mono Se substitution shows up in two positions at a ratio of 3.79:1.00 and this substitution has a dramatic effect on the conformation adopted by the triphenylene skeleton. As in the un-substituted derivative, both the central ring and the three outer rings are planar (rms deviations from planarity of 0.0074(23), 0.0098(23) 0.0119(30) and $0.0053(30) \AA$, respectively for the central ring and three outer rings). However, while in the un-substituted derivative there are clearly rings $\mathrm{A}, \mathrm{B}$ and $\mathrm{C}$ based on distortions from planarity, in the present case all the carbon atoms form one outer ring (C13 C14 C15 C16 and $\mathrm{C} 17)$ deviate from the central in the same direction but this is not true for the other two outer rings. In the case of the ring composed of $\mathrm{C} 1 \mathrm{C} 2 \mathrm{C} 3 \mathrm{C} 4$ $\mathrm{C} 5$ and $\mathrm{C} 6$, the atoms $\mathrm{C} 2$ and $\mathrm{C} 3$ deviate substantially in the opposite direction while in the other ring (C7 $\mathrm{C} 8 \mathrm{C} 9 \mathrm{C} 10 \mathrm{C} 11$ and $\mathrm{C} 12$ ) the outermost two atoms, $\mathrm{C} 10$ and $\mathrm{C} 11$ have only small deviations but in opposite directions (0.0061(66) and -0.0239(77) $\AA$, respectively). There are similar changes in the bond lengths. While in the central ring there is a similar pattern of alternating shorter and longer $\mathrm{C}-\mathrm{C}$ bond lengths, in the outer rings the pattern is not so clearly established. This is especially the case with the ring composed of $\mathrm{C} 1$ through $\mathrm{C} 6$ where all the $\mathrm{C}-\mathrm{C}$ bonds are all of similar length. One noticeable effect of the substitution is the fact that the dihedral angles between the planes of the outer rings and the central ring $\left(0.78(25)^{\circ}\right.$ for $\mathrm{C} 1$ to $\mathrm{C} 6$, and $1.40(27)^{\circ}$ and $1.40(58)^{\circ}$ for the other two rings) are much smaller than in the un-substituted derivative. As far as the packing is concerned it appears that the substitution has not had a major effect on the $\pi-$ $\pi$ stacking compared to the un-substituted derivative (table 2).

The X-ray analysis of the second Se derivative (3-24b) (this is dealt with first as it has the lower Se substitution) was carried out at LT $(123 \mathrm{~K})$. The extent of the substitution was 0.30 Se per triphenylene molecule. As in the RT derivative previously discussed the substitution pattern shows two positions for the $\mathrm{Se}$ in an atom ratio of $1.92: 1$. Since this structure was carried out at the same temperature as for the 
Table 2. Intermolecular and interplanar distances.

\begin{tabular}{lccccccccc}
\hline & $1 \cdots 1$ & slippage & A $\cdots$ A & slippage & B $\cdots$ B & slippage & C $\cdots$ C & slippage & Cg $\cdots$ Cg \\
\hline 3 & 3.4 & 4.022 & 3.31 & 4.096 & 3.352 & 4.062 & 3.356 & 4.058 & 3.714 \\
3-24a* & 3.465 & 3.945 & 3.469 & 3.942 & & & & & 3.846 \\
$3-24 \mathrm{~b}$ & 3.388 & 4.02 & & & 3.388 & 4.049 & 3.37 & 4.063 & \\
$3-24 \mathrm{c}$ & 3.429 & 4.005 & & & 3.362 & 4.062 & 3.394 & 4.035 & \\
$3-26$ & 3.4 & 4.022 & 3.356 & 4.058 & 3.31 & 4.096 & 3.352 & 4.022 & 3.714 \\
\hline
\end{tabular}

$* \mathrm{~B} \& \mathrm{C}$

not determined

un-substituted molecule a comparison of the effect on crystal data can be made. The largest change in cell constants is for the $b$ axis where the length has changed from 12.9714(4) to 13.2092(9) $\AA$. There are similar but less dramatic lengthening of both $a$ and $c$. Consequently there is a significant increase in overall cell volume from 1137.81(6) $\AA^{3}$ to $1167.70(9) \AA^{3}$ and an increase in overall crystal density from 1.333 to 1.431 . Both the central ring and three outer rings are planar (rms deviations of 0.0040(26), 0.0065(29), 0.0071(30) and $0.0023(30) \AA$, respectively). An analysis of the deviations of the three outer rings from co-planarity with the central ring shows a similar pattern to the un-substituted triphenylene and thus atoms $\mathrm{C} 2 \mathrm{C} 3 \mathrm{C} 7 \mathrm{a} C 8 \mathrm{C} 9$ and C10a correspond to ring $\mathrm{A}, \mathrm{C} 1 \mathrm{C} 6 \mathrm{C} 15 \mathrm{C} 16 \mathrm{C} 17$ and C18a correspond to $\mathrm{B}$, while $\mathrm{C} 4 \mathrm{C} 5 \mathrm{C} 11 \mathrm{a} \mathrm{C} 12 \mathrm{C} 13$ $\mathrm{C} 14$ correspond to $\mathrm{C}$. The dihedral angles between the central rings and the outer rings are 1.13(27), 2.14(28) and $1.77(27)^{\circ}$ to $\mathrm{A}, \mathrm{B}$ and $\mathrm{C}$, respectively. As far as the metrical parameters are concerned, the central ring shows the same pattern of alternating short and long C-C bond lengths (1.464 vs $1.409 \AA$ ). In comparison with the structure of triphenylene it can be seen that the C-C bond lengths C11a C12 and C17 C18a (1.344(7) and 1.355(7) $\AA$ ) have been shortened from the corresponding bonds (1.384(4) and 1.383(4) $\AA$ ) due to the Se substitution. As far as the packing is concerned it appears that the substitution has not had a major effect on the $\pi-\pi$ stacking compared to the un-substituted derivative.

The structure of the third Se derivative (3-24c) was also carried out at $123 \mathrm{~K}$ and the extent of Se substitution was greater at $0.41 \mathrm{Se}$ per triphenylene. As in the LT derivative previously discussed, the substitution pattern shows two positions for the Se in an atom ratio of 2.13:1. Since this structure was also carried out at the same temperature as for the un-substituted molecule a direct comparison of the effect on crystal data can be made. As in the previous LT example, the largest change in cell constants is for the $b$ axis where the length has changed from 12.9714(4) to $13.3470(11) \AA$. There are similar but less dramatic lengthening of both the $a$ and $c$ axes. Consequently there is a significant increase in overall cell volume from $1137.81(6) \AA^{3}$ to $1178.14(14) \AA^{3}$ and an increase in overall crystal density from 1.333 to 1.463 . Both the central ring and three outer rings are planar (rms deviations of $0.0033(14), 0.0033(14), 0.0026(16)$ and $0.0085(16) \AA$, respectively). An analysis of the deviations of the three outer rings from co-planarity with the central ring shows a similar pattern to the un-substituted triphenylene and thus atoms $\mathrm{C} 1 \mathrm{C} 6 \mathrm{C} 15 \mathrm{a} \mathrm{C} 16 \mathrm{C} 17 \mathrm{C} 18 \mathrm{a}$ correspond to ring A, C4 C5 C11 C12 C13 C14A correspond to $\mathrm{B}$, while $\mathrm{C} 2 \mathrm{C} 3 \mathrm{C} 7 \mathrm{~A} \mathrm{C} 8 \mathrm{C} 9 \mathrm{C} 10$ correspond to $\mathrm{C}$. The dihedral angles between the central rings and the outer rings are $0.98(15), 1.94(15)$ and $2.07(15)^{\circ}$ to $\mathrm{A}$, $\mathrm{B}$ and $\mathrm{C}$, respectively. As far as the metrical parameters are concerned the central ring shows the same pattern of alternating short and long $\mathrm{C}-\mathrm{C}$ bond lengths (1.464 vs. $1.409 \AA$ ). Otherwise there is very little difference between the two LT structures. As far as the packing is concerned, it appears that the substitution has not had a major effect on the $\pi-\pi$ stacking compared to the un-substituted derivative (figures 3 and 4).

For the structure of the LT tellurium derivative (3-26), the extent of substitution is very small (0.02) but clearly seen in the NMR and MS data (vide supra). In this case there is only one site seen in the structure analysis (figure 5). Unlike the other four structures, this structure was collected with Mo radiation. The cell constants are not significantly different from the unsubstituted derivative. Both the central ring and three outer rings are planar (rms deviations of 0.0049(7), 0.0036(7), 0.0025(7) and 0.0064(7) A, respectively). An analysis of the deviations of the three outer rings from co-planarity with the central ring shows a similar pattern to the un-substituted triphenylene and thus atoms $\mathrm{C} 5 \mathrm{C} 6 \mathrm{C} 15 \mathrm{C} 16 \mathrm{C} 17 \mathrm{C} 18$ correspond to ring A, C3 C4 C11 C12 C13 C14 correspond to B , while C1 C2 C7 C8 C9 and C10 correspond to C. The dihedral angles between the central rings and the outer rings are $1.28(7), 2.11(7)$ and $2.53(7)^{\circ}$ to $\mathrm{A}, \mathrm{B}$, and 


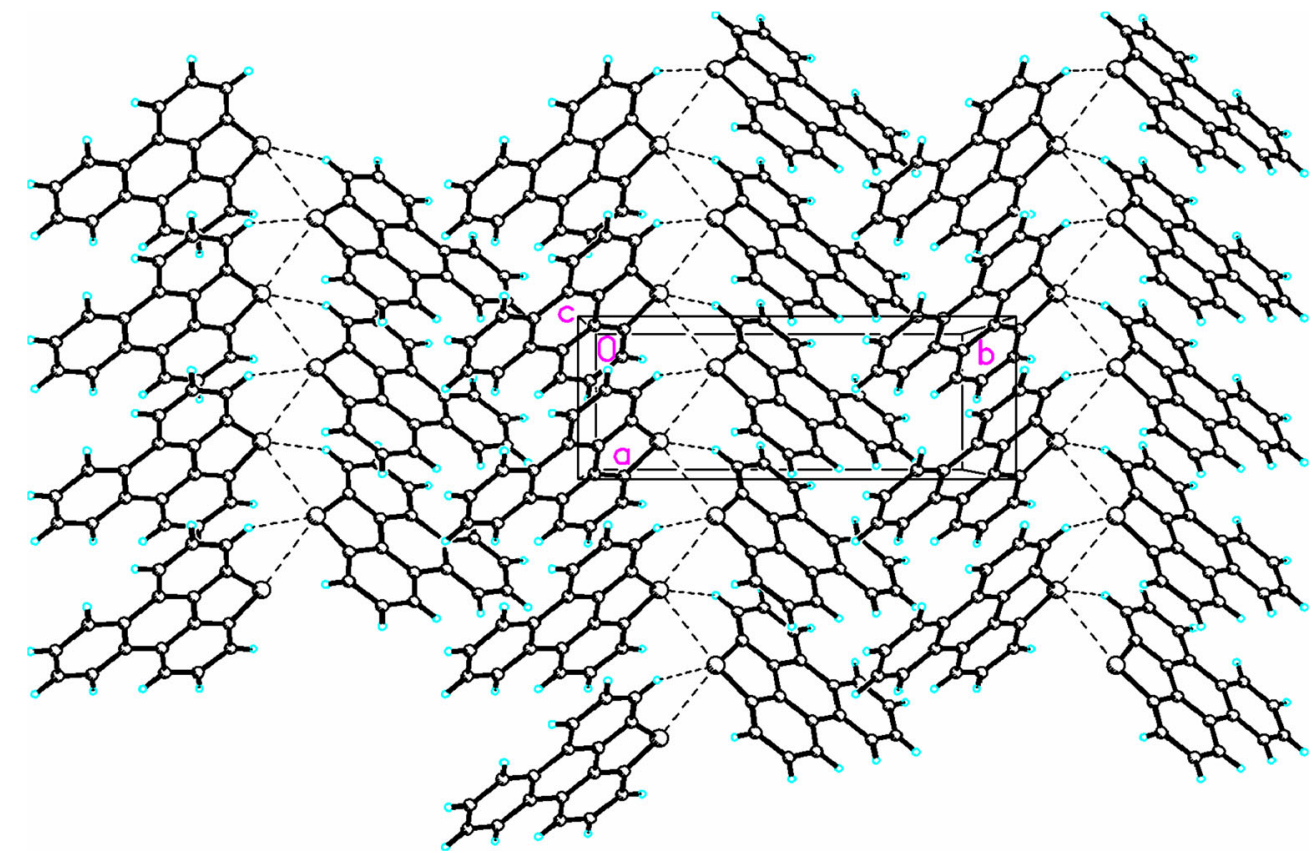

Figure 3. Packing diagram showing only 24 Se $\cdots$ Se distance 3.291(3) A, Se - ·H distance $2.80 \AA[1 / 2+\mathrm{x}, 1 / 2-\mathrm{y}, 1-\mathrm{z}]$, Se $\cdots$ Se $\cdots$ Se angle $106.5(4)^{\circ}$.

$\mathrm{C}$, respectively. As far as the metrical parameters are concerned the central ring shows the same pattern of alternating short and long C-C bond lengths (1.4625 vs. $1.4099 \AA$ ). Otherwise there is very little significant difference between the substituted and un-substituted structures. As far as the packing is concerned it appears that the substitution did not have a major effect on the $\pi-\pi$ stacking compared to the un-substituted

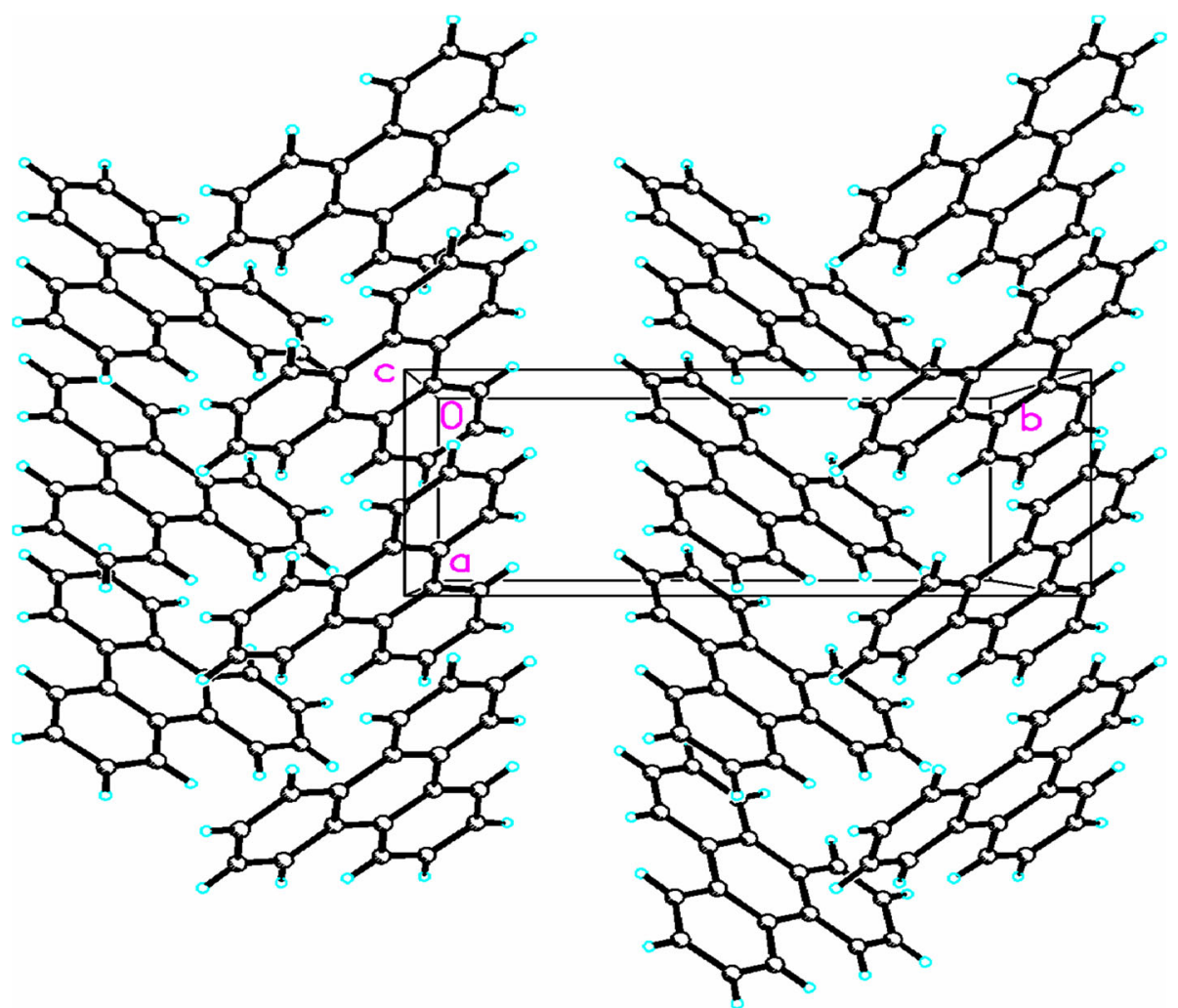

Figure 4. Packing diagram of the co-crystallized triphenylene. 


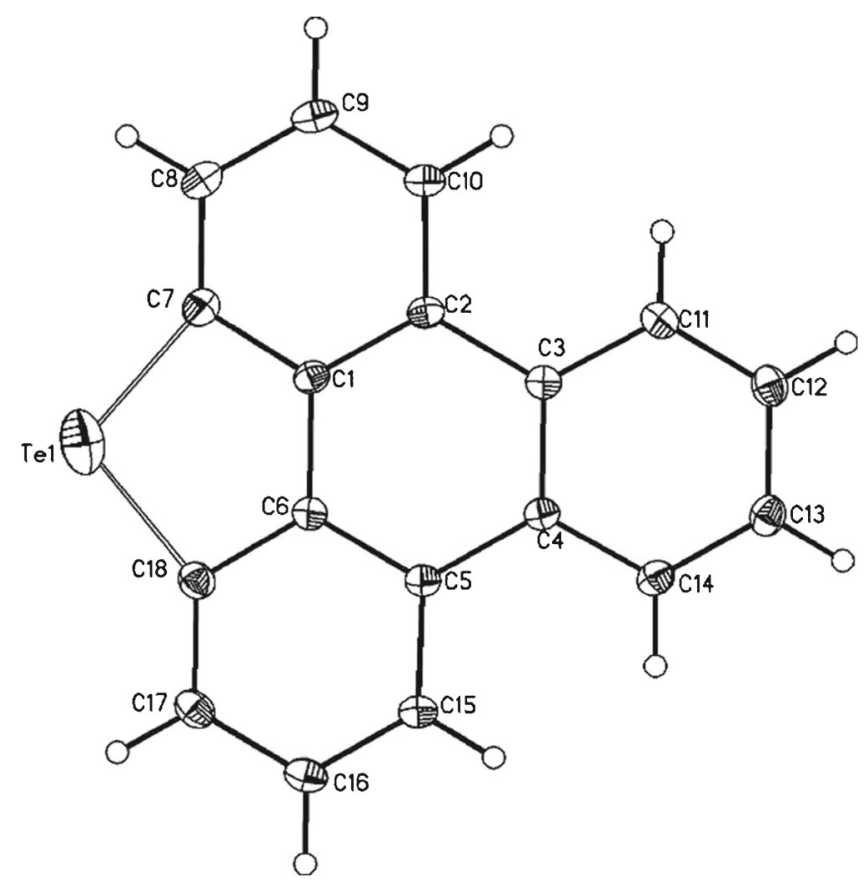

Figure 5. Molecular structure of 26: Selected bond $(\AA)$ lengths and bond angles $\left(^{\circ}\right)$ : Te-C7 1.951(5), Te-C7 1.956(5), C18-Te-C7 97.2(2).

derivative (figure 6). The packing diagram of molecule 3-26 shows Te...Te intermolecular interaction with bond distances of 2.963(6) $\AA$ which are shorter than the sum of van der Waals radii of Te $(4.30 \AA)$. The Te...Te bond distance $(2.963(6) \AA)$ is significantly shorter than that observed for dimethoxytellurophene (3.803-4.04 $\AA) .{ }^{25}$ As seen in the table of $\pi \ldots \pi$ Interactions (table 1), there are very little significant differences in the packing between the un-substituted triphenylene and mono-Te derivative, reflecting the fact that the overall structure has not been perturbed by the low occupancy of $\mathrm{Te}(0.02)$. The perpendicular separation of the central planes is $3.400(6) \AA$ and the centroid to centroid distance for both is 3.714(6) $\AA$. For the RT structure (3-24a), there is increased separation of the planes as well as centroid to centroid distances. For the two LT Se structures (3-24b and 3-24c), again there is a minor increase in interplanar separation.

\section{Conclusion}

Synthesis of organoselenium and -tellurium containing polyaromatic hydrocarbon derivatives has been attempted. Due to the larger size of selenium and tellurium, it is difficult to introduce them at the peripheral positions of triphenylene. Elemental analysis and single crystal X-ray structure analysis of organoselenium compound indicates that these always synthesize as a mixture of three components $\mathbf{3}$ and $\mathbf{2 4}$ and it is too difficult to separate them. Similar, results were also observed for the tellurium derivative 26 ( 3 and 26 mixture). Alongside, the synthesis of monoselenide $\mathbf{2 2}$ and selenocyanate $\mathbf{2 3}$ derivatives has been achieved.

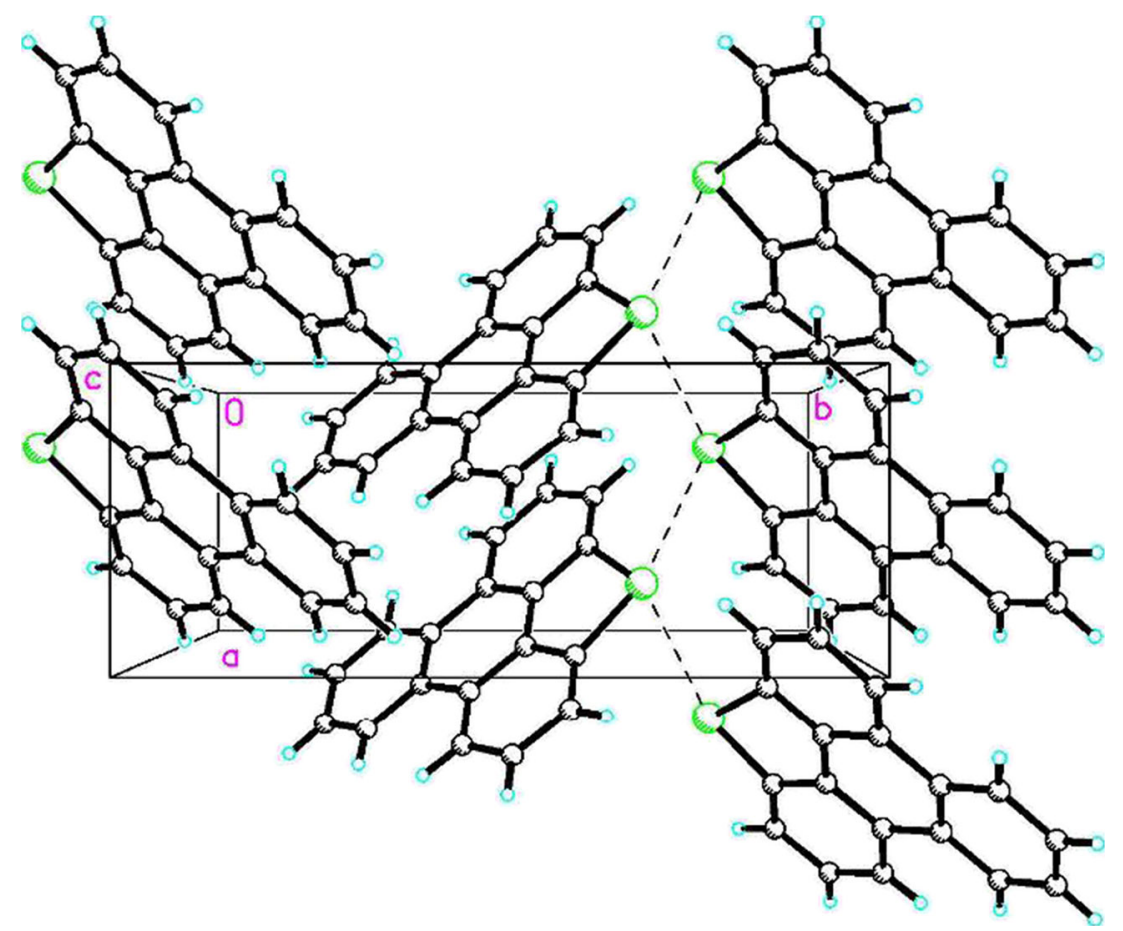

Figure 6. Two-dimensional packing diagram of 26. 


\section{Supplementary Information}

CCDC-1004393(3), CCDC-990989(3-24a), CCDC-99 0990(3-24b), CCDC-990991(3-24c), CCDC-990992 (3-26) contains the supplementary crystallographic data for this paper. These data can be obtained free of charge from The Cambridge crystallographic Data Centre via www.ccdc.cam.ac.uk/data_request/cif.

\section{Acknowledgements}

HBS is grateful to the Department of Science and Technology (DST), New Delhi (India), for generous funding. PRP is thankful to Department of Chemistry, IIT Bombay for a teaching assistantship.

\section{References}

1. Wu Y-T and Siegel J S 2006 Chem. Rev. 1064843

2. Tsefrikas V M and Scott L T 2006 Chem. Rev. 1064868

3. Van Dijk J T M, Hartwijk A, Bleeker A C, Lugtenburg J and Cornelisse J 1996 J. Org. Chem. 611136

4. Sakurai H, Daiko T, Sakane H, Amaya T and Hirao T $J$. Am. Chem. Soc. 12711580

5. Sakurai H, Daiko T and Hirao T 2003 Science 3011878

6. Higashibayashi S and Sakurai H 2008 J. Am. Chem. Soc. 1308592

7. Tanaka H N T and Mikawa H 1982 Chem. Lett 1841

8. Murschall R G H and Monch W 1982 Chem. Lett 727

9. Murschall R, Gant H and Mönch W 1982 Solid State Commun. $\mathbf{4 2} 787$
10. Li X, Zhu Y, Shao J, Wang B, Zhang S, Shao Y, Jin X, Yao X, Fang R and Shao X 2014 Angew. Chem. Int. Ed. 53535

11. Wei J, Jia X, Yu J, Shi X, Zhang C and Chen Z 2009 Chem. Commun. 4714

12. Sheldrick G M SHELXS-97, Program for Crystal Structure Solution University of Göttingen, 1997

13. Sheldrick G M SHELXL-97, Program for Crystal Structure Refinement; University of Göttingen, 1997

14. International Tables for X-ray Crystallography Vol 4 1974 (Birmingham: Kynoch Press)

15. Wei J, Gao Y, Ma X, Jia X, Shi X and Chen Z 2010 Chem. Commun. 463738

16. Selvakumar K, Singh H B, Goel N, Singh U P and Butcher R J 2011 Dalton Trans. 409858

17. Panda A, Menon S C, Singh H B and Butcher R J 2001 J. Organomet. Chem. 6287

18. Müller J and Terfort A 2006 Inorg. Chim. Acta 359 4821

19. Klemm L H, Hall E, Cousins L and Klopfenstein C E 1987 J. Heterocyclic Chem 241749

20. Imamura K, Takimiya K, Otsubo T and Aso Y 1999 Chem. Commun. 1859

21. Srivastava K, Shah P, Singh H B and Butcher R J 2011 Organometallics 30534

22. Ahmed F R and Trotter J 1963 Acta Cryst 16503

23. Zyss J, Ledoux-Rak I, Weiss H -C, Blasser D, Boesse R, Thallapally P K, Thalladi V R and Desiraju G R 2003 Chem. Matt. 153063

24. Collings J C, Roscoe K P, Thomas R L, Batsanov A S, Stimson L M, Howard J A K and Marder T B 2001 New J. Chem. 251410

25. Patra A, Wijsboom Y H, Leitus G and Bendikov M 2009 Organic Letters 111487 